\title{
DOS VISIONES HISPANO-MEDIEVALES DE UN CUENTO DEL EGIPTO FARAÓNICO: VARIACIONES DE ABŪ HĀMID AL-GARNĀṬ̄ Y JUAN RUIZ DE ALCALÁ, ARCIPRESTE DE HITA, SOBRE EL PRÍNCIPE PREDESTINADO
}

\author{
José M. ${ }^{a}$ Bellido MoRILlaS
}

Universidad de Granada

\section{RESUMEN}

El cuento egipcio ramésida de «El príncipe predestinado» conoce una versión griega, por Diodoro de Sicilia, una versión árabo-egipcia, recogida por Abū Hāmid al-Garnāțī, y una versión castellana, por Juan Ruiz de Alcalá, más relacionado con las versiones persas (según Edgar Knowlton) que con las neo-latinas y celtas. Esta presencia del cuento en España puede completarse con la moderna traducción de José Ramón Mélida. En el presente artículo estudiaremos las relaciones de las dos versiones hispanas con el texto prototípico. Haremos continua referencia a la sabiduría del erudito del siglo XIX Marcelino Menéndez y Pelayo.

Palabras clave: Diodoro, Garnati, Egipto, Hita, Doluca.

TWO MEDIEVAL HISPANIC VIEWS OF A STORY OF EGYPT IN THE

PHARAONIC ERA: VARIATIONS OF ABÜ-HĀMID AL-GARNĀTi

AND JUAN RUIZ DE ALCALÁ, ARCHPRIEST OF HITA, ON THE STORY OF THE PREDESTINED PRINCE

\begin{abstract}
The Ramessid Egyptian tale «The Doomed Prince» had a Greek version, by Diodorus Siculus, an Islamic Egyptian version, collected by Abū Hāmid al-Garnātị, and a Castillian version, by Juan Ruiz of Alcalá, related to the Persian versions (following Edgar Knowlton) more than to the Celtic and neo-Latin ones. This pressence of the tale in Spain can be completed with the modern version of José Ramón Mélida. In this article we will study the relation of the Hispanic versions with the prototypic text. The wisdom of the wonderful 19th-century scholar Marcelino Menéndez y Pelayo will be continuously alleged.
\end{abstract}

Key-words: Diodorus, Garnati, Egypt, Hita, Daluka.

El pasaje más fatalista de Juan Ruiz es sin duda el del hijo del rey moro Alcaraz. El fatalismo es uno de los muchos tópicos que integran el gran tópi- 
co del orientalismo. Por oriental tomaron este enxiemplo José Amador de los Ríos, Marcelino Menéndez y Pelayo y Julio Puyol y Alonso (en nuestro siglo, J. Corominas, J. P. Wickersham Crawford y J. B. Bruce), y, a pesar de que Félix Lecoy no los tomara en serio ${ }^{1}$, es innegable no sólo que los precedentes orientales existen ${ }^{2}$, sino que tanto el ejemplo castellano como el cuento egipcio que es su incuestionable prototipo («El príncipe predestinado», Pap. Harris 500) se revisten de orientalismo.

Un orientalismo dentro del Oriente, si adoptamos la perspectiva geográfica de los estudiosos americanos, que incluyen, antietimológicamente, el Magreb en el Oriente (y Juan Ruiz roza el Magreb). Para el caso del cuento conservado en el papiro, es patente que, si bien por el título real de su padre el príncipe predestinado es egipcio, la acción se desarrolla en Naharina, tierra de los hurritas, Mitanni; aunque el topónimo también puede estar usado desde una perspectiva «orientalista» amplia, e indicar vagamente toda la región de Siria.

Hemos decidido ilustrar este artículo con la traducción ${ }^{3}$ que hizo del francés José Ramón Mélida (1856-1933), director del Museo Arqueológico Nacional y del de Reproducciones Artísticas, destacado investigador (nomen est omen, o casi) de las ruinas de Mérida y autor de una Historia del arte egip-

\footnotetext{
${ }^{1}$ LECOY, Félix. Recherches sur le Libro de buen Amor de Juan Ruiz archipretre de Hita. Deyermond, A. D. (ed.). Westmead: Gregg International, 1974, 160 pp.

${ }^{2}$ Cfr. KNOWLTON, Edgar. «Two Oriental Analogues of Juan Ruiz's Story of the Horoscope». En Romance Notes. XV, 1973-74, pp. 183-187, que con sus paralelos persas parece dar la razón a MENÉNDEZ Y PELAYO, Marcelino. Historia de los heterodoxos españoles. Madrid: La Editorial Católica, 1978, p. 588: «Las artes mágicas de los muslimes ibéricos, como toda su civilización, eran de acarreo. Lo de menos era el elemento arábigo. A éste podemos atribuir los amuletos y talismanes con signos y figuras emblemáticas, pero el fondo principal de las supersticiones (fuera de las que son comunes a todos los pueblos y razas y las que el Corán autoriza en medio de su rígido monoteísmo, v.gr., la de ciertos espíritus o genios que no son ni ángeles ni hombres, el poder de los maleficios, el de las influencias lunares, etc.) está tomado de creencias persas y sirias, que en esta parte se amoldaban bien al principio fatalista. Influencia oriental, pues, y no árabe, ni siquiera semítica, puesto que el poderoso elemento persa, la tradición de los Magos, es arya, debemos llamar a la que traen a España los musulmanes y propagan los judíos, a pesar de las severas prohibiciones de su ley». Cfr. tb. MALLORQUÍ RUSCALLEDA, E. «El príncipe predestinado por la astrología. Tradición y fortuna de un motivo literario y folclórico». En FREIXAS, M. IRISO, S. (eds.). Actas del VIII Congreso de la Asociación Hispánica de Literatura Medieval. Santander, 22-26 de septiembre de 1999. Santander: Consejería de Cultura del Gobierno de Cantabria/ Año Jubilar Lebaniego/ Asociación Hispánica de Literatura Medieval, 2000, pp. 1161-1174, referencia que conozco gracias a la inmensa amabilidad de María Jesús Lacarra, quien a su vez disertó sobre «El cuento de los astrólogos y el hijo del rey Alcaraz (Libro de buen amor, 128-141) entre Oriente y Occidente». En Seminario internacional Incontro di culture: La narrativa breve nella Romània medievale celebrado en la Universidad de Verona del 29 al 30 de mayo de 2006.

${ }^{3}$ MÉLIDA, José Ramón. «Un cuento egipcio (versión castellana de la traducción de un papiro egipcio del Museo Británico)». En La Ilustración Española y Americana. Madrid: 28 de febrero de 1883, 7, 27, pp. 131-134.
} 
cio (Madrid, 1897). Hoy la Universidad Complutense de Madrid mantiene una Cátedra de Egiptología con su nombre.

Daniel Casado Rigalt escribe de él: «Su afición por la egiptología, que apenas contaba con tradición en España, se vió refrendada y estimulada por sus profesores Manuel de Assas y Juan de Dios Rada y Delgado, que prolongaron sus aptitudes como egiptólogo desde muy joven ${ }^{4}$. La tradición egiptológica en España es bastante antigua. Uno de los autores que vamos a estudiar, Abū Hāāmid al-Garnāțī, recuerda de su estancia en Egipto ${ }^{5}$ :

Un día encontré un lío de trapos atados fuertemente y muy deteriorados por el tiempo, que mediría más de 100 codos. Fui separando las telas agujereadas hasta que aparecieron bajo ellas unas tiras de tejido blanco de algodón, semejantes a vendas, con bordados en seda roja y perfectamente conservadas. En su interior encontré una paloma, cuyo cuerpo y plumas estaban intactos, como si acabara de morir.

\section{También encontramos textos como este:}

\& la çibdad de Alexandria es una çibdad grande, ribera de la mar, e es una de las çibdades maravillosas del mundo, que ay mucha mas obra debaxo de tierra, cuevas labradas de boveda, muchas \& muy grandes \& anchas, que pasan de las unas a las otras \& non pueden entrar dentro sinon con mucha lunbre de candelas; e pueden ir dos leguas \& tres debaxo destas cuevas \& fallan alla dentro tallaças de laton \& de marmol, de figuras de animales de camellos \& de vacas \& de bestias fieras \& de aves \& de omnes; otrosi se falla en ellas thesoros escondidos \& muchas sepulturas de marmol \& de aranbre \& aun algunas de oro \& en cada sepultura un omne muerto \& esta tal como el dia que fue y puesto \& algunos ay que tienen el cuero seco pegado con el hueso \& la grasa del corrido en la sepultura; e destas fuesas sacan la momia, que es una espeçia de que se sirven los çirujanos en las curas de las quebraduras \& otras cosas; \& en algunas fuesas se fallan collares de plata \& de piedras preçiosas \& oro \& plata que tenia cada uno de aquellos muertos, segund el grado de cada uno. E esta escripto en la mas de las sepulturas en letras griegas: «este es fulano, rey \& este es fulano, conde \& bivio tantos annos» ${ }^{6}$.

La interpretación de los jeroglíficos podría ser familiar hasta para un sargento chusquero ${ }^{7}$ :

Los egypcios declaravan sus pensamientos por imágines que representassen lo que querían y, assí, para dezir que un negocio se hiziesse con mucha presteza, pintavan un gabilán y un crocodilo para sinificar mal, y el perro que halaga con la cola

${ }^{4}$ CASADO RIGALT, Daniel. «José Ramón Mélida, un arqueólogo entre dos estilos». En Gerión, 2006, 24, 1, pp. 371-404, p. 379.

${ }^{5}$ ABŪ HĀĀMID AL-GARNĀṬ̂̄. Tuhfat al-albāb (El regalo de los espíritus). Ramos, Ana (ed.). Madrid: CSIC, 1990, p. 52.

${ }^{6}$ ANÓNIMO. Libro de astrología. Herrera, María Teresa; Sánchez, María Nieves (eds.). Salamanca: Universidad, 2000 , fol. $36 v^{\circ}$.

7 ÁLAVA DE VIAMONT, Diego. El perfecto capitán. Blas Nistal, Cristina (ed.). Salamanca: Cilus, 2000 , fol. $64 v^{\circ}$. 
para mostrar el tiempo venidero; y para sinificar la justicia pintavan un ojo; y la tierra un buey; y la libertad una mano estendida; y la avaricia una mano apretada. De lo qual, latamente trata Patricio Valeriano en su Geroglífica, donde se podrá ver este modo de escrivir.

Pero la egiptología entendida como algo más que desenvolver momias y hacer elucubraciones ingeniosas sobre pajarillos llegó a España más tarde, y de manos de extranjeros. No es deshonroso ni resta mérito, por ejemplo, a la Compañía de Jesús, docta fundación española que tuvo entre sus hijos al polígrafo Kircher: el hecho es que extranjero (francés) fue quien desveló los jeroglíficos y convirtió los estudios del Antiguo Egipto en una ciencia efectiva, y no en un mero turismo destructivo del que, desde luego, tampoco pudo participar José Ramón Mélida, ya que no pisó Egipto hasta 1909.

Prometemos dos versiones hispanas del cuento de El príncipe predestina$d o$ en el título, pero en realidad daremos tres. Esta traducción de 1883 es también un texto histórico, a pesar de su cercanía en el tiempo, y no es en absoluto una versión neutra. La ciencia del siglo XIX sufre a veces más limitaciones que en eras anteriores. Mélida anota: «Por razones que comprenderá el lector fácilmente, nos hemos permitido modificar algunas frases, las cuales van escritas con bastardilla» ${ }^{8}$. Pues bien, esta frase es sólo una, y no, no le costará al lector comprender. Curiosamente, en francés es «Il coucha avec sa femme pendant la nuit» ${ }^{9}$, forma bastante inocua (además, precisa que fue durante la noche y, con toda seguridad, con la luz apagada).

Hemos mantenido también la ortografía y la composición, para demostrar que el español decimonónico no está tan cerca del nuestro como cabría pensar. Pero, sobre todo, hemos mantenido la redacción, que desvela un aire de familiaridad con un gran novelista, incipiente orientalista y patrono de estos estudios en España: Don Juan Valera. Un desagradable aire familiar, ciertamente, ya que el parecido no está en su sutileza ni en el vuelo de su imaginación, sino en un pecaminoso laísmo y leísmo, agravado por ser Valera andaluz y proceder estos vicios de una desmañada y abracadabrante especulación gramatical de salón.

Damos paso, sin más excursos, al cuento:

Habia una vez un rey á quien no nacia hijo varon. Su corazon se puso todo en-
tristecido, y pidió un muchacho á los dioses de su tiempo. Los dioses decretaron
que le naciese uno: compartió con su esposa el lecho durante la noche, y entónces
ella concibió; cumplidos los los meses para el nacimiento, hé aquí que nació un
niño varon. Cuando las Hathors vinieron á señalarle un destino, dijeron: «iQue
sea muerto por el cocodrilo ó por la serpiente, y sino, por el perro!». Cuando las
gentes que estaban con el niño lo hubieron escuchado, fueron á decírselo á Su

${ }^{8}$ MÉLIDA, José Ramón. «Un cuento egipcio (versión castellana de la traducción de un papiro egipcio del Museo Británico)». En La Ilustración Española y Americana. Madrid: 28 de febrero de $1883,7,27$, n. $^{\circ} 2$, p. 171.

${ }^{9}$ MASPERO, Gaston. Contes populaires de l'Égypte Ancienne. $4^{\mathrm{a}}$ ed. París: 1911, p. 197. 
Majestad v., s., $f$., y á Su Majestad v., s., $f$. se le puso el corazón todo entristecido. Su Majestad v., s., $f$. le hizo construir una casa elevada sobre la montaña, provista de hombres y de todas las cosas buenas de la vivienda del rey $v$., $s ., f$., pues el niño no salia. Y cuando el niño fue mayor, subió á la terraza de su casa, y percibio un perro que marchaba detrás de un hombre, el cual iba por el camino. Dijo á su paje, que estaba con él: «¿Qué es eso que marcha detrás del hombre que va por el camino?» El paje le dijo: «iEso es un perro!» El niño le dijo: «QQue me traigan uno exactamente igual!»El paje fué á repetírselo á Su Majestad $v$., $s ., f$., y Su Majestad v., s., $f$. dijo: «iQue se le lleve un podenquillo, pues tengo miedo de que su corazon se aflija!» Y hé aquí que se le llevó el perro. Y luégo que los dias hubieron pasado alli, cuando el niño hubo tomado edad en todos sus miembros, envió un mensaje á su padre, diciendo: «Ea, ¿por qué estar como los holgazanes? Pues estoy destinado á tres destinos abrumadores, ¿no he de obrar nunca según mi voluntad? En cuanto á Dios, ique obre según su voluntad!» Escuchado cuanto decia, se le dió toda suerte de armas; diosele tambien su perro para que le siguiera; se le transportó a la costa oriental; se le dijo: «iEa!, vé á donde desees». Su perro estaba con él; caminó, según su capricho, á traves del país, viviendo de las primicias de toda la caza del país. Habiendo llegado para pasar hácia donde se hallaba el Príncipe de Naharanna, hé aquí que no habia nacido niño alguno al Príncipe de Naharanna, salvo una hija. Pero habiéndola éste construido una casa, cuyas setenta ventanas distaban del suelo setenta codos, hizo traer á su presencia todos los hijos de los príncipes del país de Khar, y les dijo: «A aquel que alcance la ventana de mi hija, ésta le será dada por esposa».

Pero muchos dias despues de cumplidos estos sucesos, miéntras los príncipes de Siria estaban en su ocupacion cuotidiana, como el Príncipe de Egipto viniera á entretenerse al lugar deonde ellos se hallaban, condujeron al Príncipe á su casa, dieron provision á su escolta, hicieron toda suerte de extremos por el Príncipe: le perfumaron, le ungieron los piés, le dieron de sus panes, le dijeron á modo de conversacion: “¿De dónde vienes, buen jóven?” El les dijo: "Yo soy hijo de un oficial de carros del país de Egipto. Mi madre murió; mi padre tomó otra mujer. Cuando sobrevinieron los hijos, ella me tomó ódio, y yo me he escapado de delante de ella". Le estrecharon en sus brazos, le cubrieron de besos.

«Pero despues que hubieron pasado muchos dias allí, dijo á los príncipes: “¿Qué haceis, pues, vosotros aquí?" Ellos le dijeron: "Nosotros pasamos nuestro tiempo en hacer esto: probamos á subir, y al que alcance la ventana de la hija del Príncipe de Naharanna, le será dada por mujer". El príncipe les dijo: "Si os place, conjuraré á los dioses, é iré á probar la subida con vosotros". Fueron á probar la subida, cual era su ocupacion de cada dia, y el Principe se subió para ver, y la figura de la hija del Príncipe de Naharanna se volvió hácia él. Pero luégo que los dias hubieron pasado alli, el Principe fue á probar la subida con los hijos de los jefes, y subió y alcanzó la ventana de la hija del jefe de Naharanna; ella le besó y abrazó cariñosamente.

Fueron para regocijar el corazon del padre de la Princesa, y le dijeron: «Uno de los hombres ha alcanzado la ventana de tu hija». El príncipe interrogó al mensajero, diciendo: «¿El hijo de cuál de los Príncipes?» Se le dijo: «El hijo de un oficial de caballería, que ha venido fugitivo del país de Egipto por escapar de su madrastra, cuando ésta tuvo hijos». El Príncipe de Naharanna se puso muy encolerizado. Dijo: «¿De manera que yo he de dar mi hija al fugitivo del país de Egipto? ¡Que se marche!» Se fue á decir al Príncipe: «Vuélvete al lugar de donde has venido». Pero la Princesa le asió y juró por Dios, diciendo: « Por Frá Harmakhuti! Si me le arrancan, no comeré más, no beberé más, moriré en segui- 
da». El mensajero se fue para repetir todos los discursos con que ella habia provocado á su padre, y el Príncipe envió gentes para matar al jóven miéntras éste estaba en su casa. La Princesa les dijo: «iPor Frá, si se le mata, al ponerse el sol moriré; no pasaré una hora más de vida ántes de permanecer separada de él!» Se le fué á decir á su padre. El Principe hizo traer al jóven con la Princesa. El jóven fue presa de terror cuando vino ante el Principe; pero éste le abrazó, le cubrió de besos y le dijo: «Cuéntame quién eres, pues hé aquí que tú eres para mí un hijo»: el jóven dijo: «Yo soy el hijo de un oficial de caballería del país de Egipto. Mi madre murió; mi padre tomó otra mujer. Ella me tomó ódio, y yo he huido delante de ella». El jefe le dió á su hija por mujer; le dió casa, vasallos, campos, tambien bestias y toda suerte de cosas buenas.

Pero despues que los dias hubieron pasado alli, el jóven dijo á su mujer: «Yo estoy predestinado á tres destinos: el cocodrilo, la serpiente, el perro». Ella le dijo: «Que se mate al perro que te pertenece». El la dijo: «Si te place, no mataré mi perro, pues le he enseñado cuando era pequeño». Ella temió por el marido mucho, mucho, y no le dejó más salir solo. Se ........ y se condujo al Príncipe hácia la tierra de Egipto, para pasear á traves del país. Pero hé aqui que el cocodrilo del rio salió del rio, y vino al medio de la ciudad en que estaba el Príncipe. Se le encerró en una casa, donde habia un gigante. El gigante no dejaba salir al cocodrilo, y cuando el cocodrilo dormia, el gigante salia á pasear. Y cuando el sol salia, el gigante entraba en la casa, y esto todos los dias, durante un intervalo de un mes, dos dias.

Y luégo que todos los dias hubieron pasado alli, el Principe se quedó en casa para divertirse. Venida la noche, el Principe se acostó sobre su estera, y el sueño se apoderó de sus miembros. Su mujer llenaba un .......... Cuando una serpiente salió de su agujero para morder al Principe, hé aquí que su mujer estaba cerca de él, mas no acostada. Entónces los sirvientes dieron leche á la serpiente; ésta se detuvo, se embriagó, quedó tendida con el vientre hácia arriba, y la mujer la hizo perecer á los golpes de su pica. Se levantó el marido, quien fué presa del asombro, y ella le dijo: «iMira, tu dios ha puesto uno de tus destinos en tus manos; él te pondrá los otros!» El presentó ofrendas á Dios, le adoró y exaltó su poder todos los días de su vida.

Y despues que los dias hubieron pasado allí, el Principe salió para pasear por las inmediaciones de su dominio; y como nunca salia solo, hé aquí que su perro estaba detrás de él. Su perro tomó campo para perseguir la caza, y él se puso á correr detras de su perro. Cuando hubo llegado al rio, descendió hácia la orilla del rio en seguimiento de su perro, y entónces salió el cocodrilo y le forzó á ir hácia el lugar donde se hallaba el gigante. Este salió y salvó al Principe: entónces el cocodrilo dijo al Principe: «iAh! Yo, yo soy tu destino que te persigue; pues, hagas lo que hagas, serás traido á mi camino (?) hácia mi y el gigante. Mas hé aquí que yo quiero dejarte ir; si el ......... tú sabrás que mis hechizos han triunfado y que el gigante ha sido muerto, ¡verás tu muerte!» Y cuando la tierra fué alumbrada y un segundo dia fué, cuando vino...

La explosión de un polovorín en Alejandría afectó al texto (del que sin embargo se dice que fue descubierto intacto), y no sabemos cómo termina el cuento. Gaston Maspero y J. Honti sugieren la posibilidad de un desenlace fatal provocado por el perro; pero son mayoría los autores ${ }^{10}$ que, como Georg Mo-

\footnotetext{
${ }^{10}$ Cfr. BRESCIANI. Letteratura e poesia dell'antico Egitto. Cultura e società attraverso i testi. Turín: Einaudi, 1999, p. 390.
} 
ritz Ebers, M. Pipers o George Posener, atendiendo al tenor de la historia y las continuas invocaciones a $\mathrm{Ra}$, abogan por un final dichoso favorecido por el dios. G. Lefebvre propone que la solución la proporcione un mago.

El cocodrilo aparece como salvador en una transfiguración de la historia recogida por Diodoro Sículo (D.S., 1.89.3), atribuida al primer rey de Egipto (aunque Cordiano y Zortat dicen que «Diodoro incorre qui in una confusione onomastica tra il faraone Menas [...] e il sovrano che altrove $(61,1-2)$ chiama Mendes e Marros, e a cui attribuisce la costruzione del cosidetto Labirinto» $)^{11}$ y desprovista de la parte de la profecía. I. E. S. Edwards juzga:

The legend, which contains obvious anachronisms, is patently devoid of historical value, an invention by priests of later times who wished to connect their cult with Menes. A scribe's palette in the Berlin Museum bears an inscription which shows that the Greek tradition crediting Menes with the construction of a temple for Ptah at Memphis dates back at least to the Nineteenth Dinasty ${ }^{12}$.

Sobre la confusión onomástica, muy atractiva es esta anotación de Creuzer sobre el príncipe Manero de Herodoto, muerto prematuramente:

Aegyptiorum Lini, qui Maneros dicatur, meminit Plutarch. de Isid. et Osir. §. 18 p. fin. [...] Phoenicium regis filium fuisse scribit, qui Issidi, mariti obitum lugenti adstans, ipse prae dolorem obierit [...] Alii astronomiae aliarumque scientiarum peritum dicebant iuvenem. Sed tesserarii quid in his inesse, vix negandum vel si nominis rationem perspexeris. Nam auctore Iablonskio vocc. Aegyptt. p. 128 seqq. Maneros indicat filium aut subolem Menis (i.e. aeterni), qui rex primus Aegypto regnasse fertur ${ }^{13}$.

Pero la lectura de Frédéric de Rougemont ${ }^{14}$, coincidente en buena medida con George Frazer ${ }^{15}$, nos desengaña pronto de tales espejismos. Y, desde luego, esa posibilidad etimológica no le era desconocida al propio Plutarco.

Cuando Abū Hāmid al-Garnātị visitó Egipto, el cuento se había transformado (y simplificado) mucho ${ }^{16}$ :

Entre las construcciones antiguas que se encuentran en Egipto destaca el llamado Muro de la Vieja, llamado así por Dulūkā, cierta reina de Egipto. Dicho muro se extiende desde al-'Arīš hasta Aswān, atravesando varias provincias orientales de

${ }^{11}$ DIODORO SíCULO. Biblioteca storica, I. Cordiano, Giuseppe; Zortat, Marta (eds.). Milán: Rizzoli, 2004, n. ${ }^{\circ 3}$, p. 379.

${ }^{12}$ EDWARDS, I. E. S. «The Early Dynsastic Period in Egypt», en The Cambridge Ancient History, I, 2. Cambridge: Universidad, 1971, p. 22.

${ }^{13}$ HERODOTO DE HALICARNASO. Herodoti Musae. Creuzer, Georg Friedrich (ed.). Leipzig: Hahn, 1830, p. 661.

${ }^{14}$ ROUGEMONT, Frédéric de. Le peuple primitif, sa religion, son histoire et sa civilisation, III. Ginebra: Joël Cherbuliez, 1857, p. 258.

${ }^{15}$ FRAZER, James George. The Golden Bough: A Study in Magic and Religion. Londres: Penguin, 1996, p. 510.

${ }^{16}$ ABÜ HĀMID AL-GARNĀṬ̄̄, Tuhfat al-albāb (El regalo de los espíritus). Ramos, Ana (ed.). Madrid: CSIC, 1990, p. 123. 
Egipto. Según los coptos, la razón por la cual se construyó este muro fue el temor de Dalūkā a que otros reyes pretendieran apoderarse de Egipto, después de que el Altísimo sumergiera al faraón y a su pueblo. Hizo además que las mujeres se casaran con los esclavos con el fin de que se multiplicara su descendencia. Según otra versión, Dalūkā dio a luz un hijo y al examinar su horóscopo vio que un cocodrilo sería la causa de su muerte. Ordenó entonces que se construyera el muro, con el fin de proteger a su hijo de los cocodrilos. Cuando el niño alcanzó la pubertad, vio en su horóscopo aquello de lo que se le protegía y sintió grandes deseos de conocerlo. Le confeccionaron entonces, en madera, la figura de un cocodrilo, y al verla, el muchacho sintió tal terror que se apoderaron de él los malos pensamientos y murió de angustia.

Como vemos, el rey egipcio ha cambiado de sexo y el cuento tiene una fecha precisa: después del paso del Mar Rojo por los israelitas. La reina Dalūka aparece en otros muchos autores árabes ${ }^{17}$. Ibn 'Abd Al-Hakam (Futuh., 4041) dice que unos atribuyen la construcción del faro a Daluka y otros a Qulbatra. Según Okasha El Daly ${ }^{18}$,

In these words we encounter an early possible confusion between two queens: Daluka (also called Zulaikha) and Cleopatra. We do not know the historicity of Queen Daluka, but her name is almost always used synonymously with that of Cleopatra. Both are said to have built the Alexandrian Lighthouse and a massive wall around all of Egypt to protect it against invasion, and Daluka was said to have built a Nilometer at Memphis. Though Cleopatra did not build the Lighthouse, her fame as a builder of great monuments gave rise to such claims in the medieval Arabic sources.

Pero naturalmente, no es tan sencillo. Dalûka no es Cleopatra ni Zulaica (el nombre que la tradición árabo-persa da a la mujer de Putifar). La confu-

${ }^{17}$ Cfr. AL-MAS 'ŪDĪ. Les prairies d'or. Barbier de Meynard, Charles y Pavet de Courteille, Abel (trad.). París: Imprimerie Impériale, 1863, p. 398, testimonio de venerable antigüedad donde se dice que Daluka construyó un muro para proteger a su hijo de animales y monstruos; QALQAŠANDĪ, A\%mad ibn 'Alī. Die Geographie und Verwaltung von Ägypten. Wüstenfeld, Ferdinand (ed.). Gotinga: Dieterich, 1879, p. 122; POPPER, William. The Cairo Nilometer. Studies in Ibn Taghri Birdī's Chronicles of Egypt. Universidad de California, 1951, I, p. 19; AL-JAFĪF Ibn, Murtadà. L'Égypte de Murtadi, fils du Gaphiph. Wiet, Gastón (ed.). París: T.V.S.O., 1953, p. 27; POPPER, William. The Cairo Nilometer. Studies in Ibn Taghri Birdì's Chronicles of Egypt. Universidad de California, 1951, I, p. 19; ANÓNIMO. Kitāb al-istibșār fī 'ajā'ib al-amșār: wașf Makkah wa-al-Madinah, wa-Miṣr wa-bilad al-Maghrib. Description de la Mekke et de Médine, de l'Égypte et de l'Afrique septentrionale, par un écrivain marocain du VIe siècle de l'Hégire (XIIe s. J.C). Sa'd Zaghlūl 'Abd al-Hamīd; Dar al-Bayda; Dār al-Nashr al-Maghribīyah (eds.). 1985, p. 266; NEMOY, Leon. «The Treatise on the Egyptian Pyramids (Tuhfat al-kirām fì khabar al-ahrām) by Jalāl al-Dīn al-Suyūṭī». Isis, 30, 1, febrero de, 1939, pp. 17-37; SAINTINE, X. B.; MARCEL, J. J.; REUBAUD, L. Histoire scientifique et militaire de l'expédition française en Égypte. París: A. J. Dénain, 1832, V, p. 4; AL-ANȘĀRĪ, Umar ibn Ibrāhīm. A Muslim. Manual of War: Being Tafrij al-karūb fī tadbìr al-hurub. Scanlon, George T. (trad.). El Cairo: American University at Cairo Press, 1961, pp. 44-45.

${ }^{18}$ EL DALY, Okasha. Egyptology. The Missing Millennium: Ancient Egypt in Medieval Arabic Writings. Londres: Routledge-Cavendish, 2005, p. 133. 
sión entre estos tres (no dos) personajes egipcios es la excepción y no la regla. Ferdinand Wüstenfeld, a quien hemos citado como editor de una de las fuentes, hace un resumen de la leyenda de Dalūka ${ }^{19}$ :

Die Weiber kamen dann überein, eine kluge und verständige Frau Namen [...] Dalûka zu ihrer Königin zu machen, sie war 160 Jahre alt, und als sie die Regierung übernahm, liess sie von Syene bis el-'Arîsch eine Mauer bauen, wodurch die Dörfer und Felder von Aegypten eingeschlossen wurden; neben die Mauer stellte sie Wachen und errichtete in allen Gegenden Glocken, damit, wenn sich ein Feind nahte, die Wachen die Glocken ziehen und die Bewohner sich dann zur Gegenwehr rüsten konnten. Reste dieser Mauer sind im Oberlande unter dem Namen «Mauer der alten Frau» noch vorhanden. Sie regierte 130 Jahre, dann starb sie und ihr folgte ein Mann von Coptischer Abkunft Namens [...] Darkûn ben Bakiutes, welcher lange Zeit auf dem Throne sass, bis er starb [...]

\section{Johann Nepomuk Sepp la identifica con la controvertida Nitocris ${ }^{20}$. Según Hamaker, reseñado por Reinaud ${ }^{21}$,}

Il résulte de toute cette discussion, que Dalouka, cette reine si fameuse chez les Orientaux, mais dont on ne trouve aucune trace chez les Grecs, represente la $19^{\mathrm{e}}$ dynastie car, comme nous venons de le voir, les Diospolitains de la $20^{\mathrm{e}}$ la suivent immédiatement, et de l'autre côté elle remplaça le Pharaon qui périt dans la mer Rouge. C'est là une circonstance sur laquelle tous les Orientaux s'accordent. Or, ce Pharaon, si nous en croyons Eusèbe, appartenait à la $18^{\mathrm{e}}$ dynastie. La longe vie de Dalouka, qui parvint à l'âge de 180 ans (la $19^{\text {e }}$ dynastie en compte 194), confirme cette conjecture.

El historiador Tino Vittorio, sicilianista, recoge además esta tradición que aproxima el personaje a las tierras del Arcipreste (y de José Ramón Mélida) ${ }^{22}$ :

La tradizione arabe vuole che Bahr al Rum prese forma in ciò che nel passato era terra asciutta, allagata dalle acque dell'Atlantico attraverso lo Stretto (poi, di Gibilterra), tagliato dai Banu Daluka, discendenti da una regina Daluka (che si suppone abbia regnato in Egitto dopo il Faraone dell'Esodo), desiderosi di interporre una barriera tra se stessi e un ignoto «re dei Greci».

${ }^{19}$ WÜSTENFELD, Ferdinand. «Die älteste Aegyptische Geschichte nach den Zauberund Wunderzählungen der Araber». En BENFEY, Theodor. Orient und Occident, insbesondere in ihren gegenseitigen Beziehungen. Forschungen und Mittheilungen. Eine Vierteljahrsschrift, Gotinga: Dieterich, 1862, I, pp. 326-341, pp. 340-341.

${ }^{20}$ SEPP, Johann Nepomuk. Jerusalem und das heilige Land: Pilgerbuch nach Palästina, Syrien und Aegypten. Schaffhausen: Hurter, 1863, p. 534 y especialmente 786.

${ }^{21}$ REINAUD. «Sur les anciennes dynasties égiptiennes, d'après les auteurs arabes; par M. Hamaker. (Note extraite de l'édition de la Chronique Arabe d'Aboulfeda antérieure á Mahomet; par M., Leipzig, 1831, p. 216 et suiv.». En Bulletin des sciences historiques, antiquités, philologie, 18, 1831, p. 301.

${ }^{22}$ VITTORIO, Tino. «Se il «Ponte» diventa un mito di comunicazione». En Provincia di Catania, 20, 5, 2002, p. 47. 
Sin embargo, Dalūka no tiene un artículo propio en la Enciclopedia del Islam de Brill, a pesar de aparecer en artículos como Manf. Tampoco en el Pauly-Wissowa, donde no aparece en artículos que se relacionarían con ella, como Nitokris.

Erik Hornung ${ }^{23}$ testimonia el paso de estas tradiciones árabes a los viajeros y polígrafos europeos, desde 1610 con George Sandys ${ }^{24}$ a, pasando por John Greaves, el muy curioso Johann Georg Herwart von Hohemburg ${ }^{25}$. También podríamos citar a Charles Thompson ${ }^{26}$ :

After all, the above-cited Authors ingenuosity confess, that there is little Agreement either among the Natives of Egypt, or ancient Historians, with respect to the Founders of any of the Pyramids we are speaking of: And the Arab Writers are under the fame Uncertainty, some attributing them to Nimrod, others to Queen Daluka, and others concluding that they must have been built before the Flood, or else the Memory of the Founders would have been better preserv'd.

La reina Dalūka se integra con total naturalidad en las «listes d'anciens rois d'Egypte, formées par des auteurs juifs ou arabes. Elles se trouvent, ou dans l'Edipe du P. Kircher, ou dans le Phaleg de Bochart» ${ }^{27}$, o en el primer volumen de la exitosa An Universal History, from the Earliest Accounts to the Present Time ${ }^{28}$. Pero sin duda alguna su aparición más celebrada fue en la novela del abate Terrasson Séthos, de 1731, convertida en tragedia ${ }^{29}$, que ins-

${ }^{23}$ HORNUNG, Erik. Das esoterische Ägypten. Múnich: Beck, 1999.

${ }^{24}$ Cfr. VYSE, Howard. Operations Carried on at the Pyramids of Gizeh in 1837: With an Account of A Voyage Into Upper Egypt, and an Appendix. Londres: James Fraser, 1840, pp. 201-201: «He adds, that it was said by some to have been built by Miserinus, the son of Cheops, or by Rhodope, whose slipper being brought by an eagle to the king, Amasis, he ordered search to be made for her, married her, and afterwards erected for her this monument».

${ }^{25}$ HOHEMBURG, Johann Georg Herwart von. Admiranda ethnicae theologiae mysteria propalata. Múnich: N. Heinrich, 1623.

${ }^{26}$ THOMPSON, Charles. The travels of the late Charles Thompson, Esq.: containing his observations on France, Italy, Turkey in Europe, the Holy Land, Arabia, Egypt, and many other parts of the world: giving a particular and faithful account of what is most remarkable in the manners, religion, polity, antiquities, and natural history of those countries: with a curious description of Jerusalem as it now appears, and other places mention'd in the Holy Scriptures: the whole forming a compleat view of the ancient and modern state of great part of Europe, Asia, and Africa. Londres: 1744, p. 278.

${ }^{27}$ GUÉRIN DU ROCHER, Pierre Marie Stanislas. Histoire véritable des temps fabuleux. París: 1824, p. 94.

${ }^{28}$ An Universal History, from the Earliest Accounts to the Present Time, I. Londres: 1779, pp. 185,340 .

${ }^{29}$ TERRASSON, Jean. Séthos. Histoire ou vie tirée des monumens anecdotes de l'Ancienne Égypte. Traduite d'un Manuscrit Grec. París: Desaint, 1767. Cfr. SCHOMANN, Emilie. Französische Utopisten und ihr Frauenideal. E. Felber, 1911, p. 76; WINCKELSTEIN, Wendelin von. Die Odyssee des Aristoteles. Eine Rezeptionsgeschichte der Neuzeit. Múnich: Winckelstein-Verlag, 1985, p. 349. 
piró muchas fantasías masónicas ${ }^{30}$ y el personaje de la Reina de la Noche en La flauta mágica de Mozart ${ }^{31}$.

Pero la presencia de Dalūka en el Occidente europeo (y no sólo en el Magrib islámico) es muy anterior a Sandys. Dejamos hablar a Marcelino Menéndez y Pelayo ${ }^{32}$ :

Nada hay que añadir respecto de la casa encantada de Toledo, a lo que con tanta erudición e ingenio acaba de escribir el señor don Juan Menéndez Pidal, a cuyo trabajo me remito. Mézclanse en esta leyenda elementos de muy varias procedencias, y es fácil notar en ella diversos estados sucesivos. A primera vista inclinaríase uno a tenerla por enteramente oriental, considerando sólo la extraña analogía que muestra con la del sepulcro de la reina Nitocris violado por Darío, con la esperanza de encontrar grandes tesoros, según puede leerse en el primer libro de las Historias de Herodoto. Nada falta para la perfecta semejanza, ni siquiera las inscripciones grabadas en la puerta del monumento fúnebre, y en el sepulcro mismo. Natural parecía que esta conseja, transmitida por los persas o los egipcios a los árabes, y enriquecida por ellos con nuevas fábulas, tal como la vemos en el cuento de los palacios de Daluca la vieja (que entró con otras narraciones de la misma procedencia en la Grande et General Estoria compilada por Alfonso X) fuese el único fundamento de todo el mito, puesto que de la reina de Egipto se cuenta, como aquí de Hércules, que estaba iniciada en el arte mágica, que fabricó los sortilegios de su palacio en el instante propicio de la revolución de los astros, y que puso en sus templos las imágenes de todos los pueblos vecinos a Egipto, con sus caballos y camellos

Sobre Egipto en general se lee en la cuarta parte de la General Estoria que

«La tierra del mundo en que a aquella sazon mas se trabaiauan del saber de las estrellas. \& o mas estrelleros \& adeuinos \& fechizeros auie; egypto era. \& por el seso. \& por el guiamiento destos andauan \& fazien todos sos fechos los Reys de Egypto \& los ricos omnes \& aun los otros pueblos» ${ }^{33}$.

En las versiones medievales del cuento del príncipe predestinado, la magia no es el desenlace, como quería Lefebvre para el relato egipcio, sino el planteamiento. Quienes hacen las profecías son conocedores de la magia, como Daluca o, en la tradición céltica y su continuación, Lailoken y Merlín. Por la

${ }^{30}$ BÉDARRIDE, Marc. De l'Ordre Maçonnique de Misraïm: depuis sa création jusqu'à nos jours, de son antiquité, de ses luttes et de ses progrés. París: Bénard, 1845, I, pp. 96-97.

${ }^{31}$ DENT, Edward Joseph. «The Queen of Night is modelled on Daluca, the stepmother of Sethos, and the three Ladies belong to her circle». Mozart's Operas: A Critical Study, Chatto \& Windus, 1913, p. 340; lo mismo, con más feminismo, en ABBATE, Carolyn. «Daluca is demonized for her constant chattering, parallel judgments resounded in contemporary misogynist discourse». In Search of Opera. Princeton: Universidad de Princeton, 2001, p. 72 .

${ }^{32}$ MENÉNDEZ Y PELAYO, Marcelino. Antología de poetas líricos castellanos. Madrid: CSIC, 1940, p. 133.

${ }^{33}$ ALFONSO X de Castilla, el Sabio (dir.). General Estoria. Cuarta parte. Sanchez-Prieto Borja, Pedro (ed.). Alcalá de Henares: Universidad, 2002, p. XXVIII. 
magia conoce Daluca el destino de su hijo, y hace prodigios y maravillas para detenerlo. Pero el destino no se deja hacer, y el final es el mismo.

En el Libro de buen amor, en cambio, se recupera la construcción teológica de la providencia de Dios presente en la más antigua versión conservada del relato:

$$
\begin{aligned}
& \text { Yo creo los astrólogos verdad naturalmente; } \\
& \text { pero Dios que crió natura e acidente, } \\
& \text { puédelos demudar, et faser otramente: } \\
& \text { segund la fe católica, yo d'esto só creyente }{ }^{34} \text {. }
\end{aligned}
$$

La fidelidad de la versión egipcia medieval, en cambio, se mide ante todo por la fidelidad a la figura del cocodrilo, lo que demuestra que la permanencia en un mismo emplazamiento geográfico no hace necesariamente demasiado bien por la conservación textual. Sería un buen argumento para todos los helenistas que, aun en nuestros días, atacan la pronunciación erasmiana y privilegian la neo-griega, diciendo que mejor sabrán los griegos cómo pronunciar su lengua que no un bárbaro del norte.

Pero en todas las disciplinas humanas hay cocodrilos autóctonos y otras especies endémicas a las que aferrarse con orgullo. 